\title{
Hormone expression in melanomas related to tumor angiogenesis
}

\author{
Bhanu I yengar \\ Pigment Cell Centre, New Delhi, India \\ Correspondence: Bhanu Iyengar. Address: Pigment Cell Centre, Iyengar Farm, Brijwasan Road, PO Kapashera, New \\ Delhi 110037, India. E-mail: bhanu_i@yahoo.com
}

Received: October 5, 2012

Accepted: October 30, 2012

Online Published: November 15, 2012

DOI : $10.5430 /$ jst.v2n6p36

URL: http://dx.doi.org/10.5430/jst.v2n6p36

\section{Abstract}

Background: Vicarious production of pituitary hormones by malignant tumors is a well-known phenomenon. Prolactin (PRL), human growth hormone (HGH), adrenocorticotropic hormone (ACTH) and alpha-melanocyte stimulating hormone $(\alpha-\mathrm{MSH})$ expression has been reported in malignant melanoma tumor cell lines. The present study examines the pattern of expression of the hormones ACTH, PRL and HGH in melanoma with regard to tumor growth and differentiation in relation to angiogenesis.

Methods: During angiogenesis the tumor cells encircle a central vessel in layers to form a tumor-vascular-complex (TVC) with a central vessel and a mantle of 5 to 6 layers. Hormone expression is assessed by immunopositivity for PRL, HGH, and ACTH in the tumor-vascular complexes, on serial frozen and paraffin sections and subjected to statistical analysis (t-test or Mann-Whitney U- test).

Results: As two layers accrue the tumor cells acquire PRL and HGH positivity and are associated with a wave of mitotic activity in these layers. Further addition of layers shows ACTH positivity in the outer layers in association with pigmentation.

Discussion: There is a coordinated growth of melanoma cells around neovascular channels, the cell cycle of malignant melanocytes being orchestrated by the three pituitary hormones, PRL, HGH and ACTH. The expression of PRL and HGH is related to mitotic activity while ACTH and pigment indicate differentiated function.

\section{Key words}

Prolactin, Human growth hormone, Adrenocorticotropic hormone, Angiogenesis

\section{I ntroduction}

Melanoma is a highly aggressive skin tumor that originates in the epidermis from melanocytes which arise from the neural crest cells during embryogenesis. The melanocytes form a UV-sensitive neural network in the skin ${ }^{[1]}$. They express melanocyte-stimulating hormone (MSH) and adrenocorticotropic hormone (ACTH) in response to UV exposure ${ }^{[2]}$. The fundamental role of MSH and corticotrophins has been established in the regulation of melanogenesis. Both prolactin (PRL) and growth hormone (GH) as well as ACTH are expressed by proliferating melanocytes and in response to UV exposure $^{[3]}$. 
Vicarious production of pituitary hormones by malignant tumors is a well-known phenomenon. PRL expression has been observed in malignant melanomas, where it has been suggested to act as a major local peptide growth promoter via autocrine/ paracrine mechanism ${ }^{[4]}$. This hormone is now recognised as a neurotrophic factor and a growth factor for many cell types in developing adult organisms. It promotes proliferation, differentiation, or survival depending on the physiological and cellular context ${ }^{[5]}$. One of the major targets of prolactin is the skin where it also stimulates skin melanocyte growth.

Strong ACTH and $\alpha \mathrm{MSH}$ expression has been reported in malignant melanoma tumor cell lines such as G-361 and DX-3, in response to external stress like UV exposure ${ }^{[6]}$. Intense and diffuse ACTH immunopositivity has been reported in samples of nodular melanoma, vertically growing acral lentiginous melanoma and superficial spreading melanoma as well as in metastatic lesions ${ }^{[7]}$.

The present study, examines the presence of the hormones ACTH, PRL and HGH in various layers of tumor cells in three dimensional tumor vascular complexes (TVC) formed in relation to angiogenesis. Pigment varies according to the differentiation of the tumor cells ${ }^{[8]}$. This criterion has been used to demarcate differentiated and undifferentiated areas.

\section{Material and methods}

27 nodular melanomas in the vertical growth phase (VGP) were received from the Cancer Surgery Unit of Safdarjung Hospital, New Delhi, fixed in 10\% formol glutaraldehyde for overnight cold fixation. Multiple blocks were taken for diagnosis. The tumors were archived after diagnosis, for further study. All tumors were banked tissues available without patient identifiers. 10 blocks were taken from both pigmented and amelanotic nodules in each tumor in proportion to the percentage pigment, which yielded equal numbers of pigmented and amelanotic nodules. The blocks were arranged in a grid in a chronologic sequence and in order of overall pigment levels as given in Figure 1.5 $\mu \mathrm{m}$ thick serial paraffin and frozen sections of each block were subjected to immunohistochemistry for localization of ACTH, PRL and HGH by the avidin-biotin method using Dako Pat kits. (HMB-45, PRL, HGH, ACTH) ${ }^{[9-11]}$. As a negative control all slides included a serial section stained with no $\mathrm{mAb}$. The same $\mathrm{mAb}$ were used simultaneously against known positive sections from human skin as positive controls.

Figure 1. [a] Blocks taken from pigmented and amelanotic nodules arranged in a grid in chronological order, 'a' marks those with tumor/stroma interphase and angiogenesis. [b] Tumors arranged according to pigment levels graded from top-left to the bottom-right with blocks studied marked 'a'.
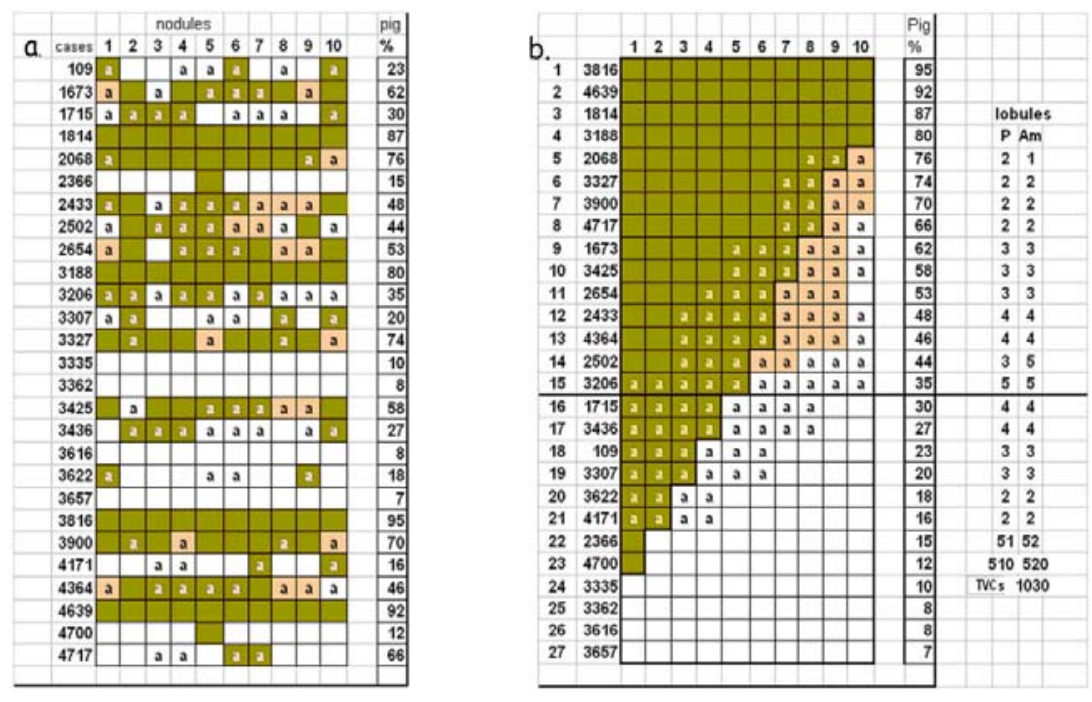

Four tumors showed uniformly high pigment which made it difficult to assess immunopositivity accurately; while 4 showed uniformly amelanotic nodules with a diffuse pattern and very low or no positivity. These tumors were not used for Published by Sciedu Press 
the present study. The remaining 19 tumors were composed of varying numbers of pigmented as well as amelanotic nodules. 103 blocks from both pigmented and amelanotic nodules were included for the study to include the interphase between the tumor and surrounding stroma with active angiogenesis, as given in Figure 1. Hormone marker positivity was examined and compared in the Perivascular Mantle Zone (PMZ) of TVC formed during angiogenesis. The fully formed TVC was composed of a central neovascular channel surrounded by a mantle of 5 to 6 layers of tumor cells.

The sequence of appearance of mAb positivity in tumor cell layers around the central vessel was recorded in a total of 870 TVC. For the final analyses of global results of all tumors, ten random well formed TVCs with 5 to 6 layers in the mantle zone were studied in serial sections of the 103 blocks for each marker. The distribution pattern of hormone positivity, in relation to the central vessel was assessed, in a total of 1030 TVCs. The layers in each TVC were numbered from L1 to L5 with layer L1 being closest to the vessel. Positivity for the hormones ACTH, PRL and HGH in each layer was marked out in Camera Lucida (CL) diagrams. The percentage positivity in each layer was mapped onto an aggregate CL figure as well in graphs, to show the localization of each hormone in relation to the angiogenic central vessel.

\section{Cell counts}

Each TVC is composed of 240 to 250 cells in the mantle zone; the innermost layer 1 around the vessel has 15 to 20 cells; the outermost layer 5 is formed of 75 to 80 cells, the ratio being 1:5. The layers showing immunopositive cells were counted for each hormone and depicted in graphs. A positive cell count was done in the positive layers and the percentages of $\mathrm{mAb}$ positive cells have been compared and presented in graphs since the layers vary in cell number.

\section{Results}

\subsection{TVC formation (Figure 2)}

As the neovascular channel enters the margin of the tumor initially a single layer of tumor cells surround the vessel. As further layers get added PRL positivity appears as the 2nd and 3rd layers form, closely associated with mitotic activity (Figure 2). As further layers add ACTH positivity appears as the outer most 4th and 5th layers are added on to form the TVC. Pigment is seen in the outermost layers and correlates with ACTH positivity. The mAb positivity as well as pigment and mitosis in the 1030 fully formed TVCs from all tumors studied are described below. There is no significant difference in layer positivity in melanotic and amelanotic nodules although the positive cell counts were very low in amelanotic areas. The histological pictures in Figures 2, 3 and 4 are from serial sections of the same tumor for appropriate comparison.

Figure 2. Development of two to three layered TVC and PRL positivity.

Sequential growth of the TVC from [a] angiogenic channel with early tumor cell interaction to [b] a single layer complex to [c] a

2 to 3 layered one to show [d] the appearance of PRL positive cells in the 2nd and 3rd layers. (mAbPRLX400)

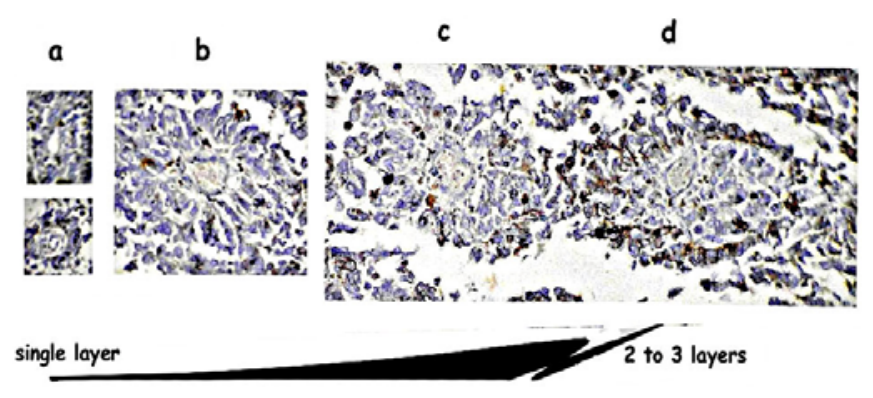

\subsection{Hormone, pigment and mitosis in fully formed TVC}

\subsubsection{Mitotic counts in TVCs (Figure 3 and 6)}




\subsubsection{Layers showing mitosis}

Mitosis is mainly concentrated in the layers L2 and L3. 903 TVCs out of $1030(87.7 \%)$ showed mitotic figures in L2 and 1022 TVCs out of 1030 (99.2\%) showed mitotic figures in L3 show mitotic figures, and 21\% TVCs (216/1030) had very occasional mitosis L4, L1 and L5.

Figure 3. A comparison of PRL positivity and mitotic activity in a 2-3 layered TVC.

[a] shows PRL positivity in the newly formed 2nd and 3rd layers. [b] The PRL positive cells have been highlighted. The outline of positive cells is shown for comparison. [c] Cells in mitosis are highlighted in grey with a comparative diagram. [d] Combined figure of PRL and mitotic figures to show the congruance. [e] A comparative graph comparing percent PRL positivity and mitosis in the three layers.
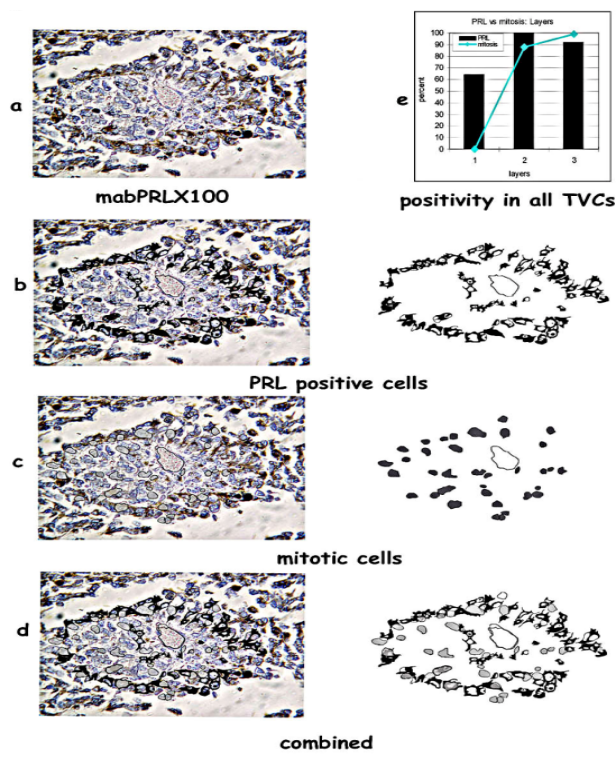

\subsubsection{Mitotic counts}

There are 12644 cells in mitosis out of 28896 cells (43.75\%) in L2; 24185 cells out of 49056 cells (49.3\%) in L3, compared to 1383 out of 13824 cells (10\%) in L4. L1 and L2 do not show significant numbers of mitotic figures.

\subsubsection{PRL (Figure 4-6)}

Figure 4. Comparison of hormonal positivity in TVCs. [a] shows PRL positivity in layers $2 \& 3$ (mAbPRLX400); [b] shows HGH positivity in similar areas although scattered as compared to PRL (mAbHGHX100); [c] ACTH positivity is seen in the peripheral layers L4 and L5 of the TVC (mAbACTHX100).

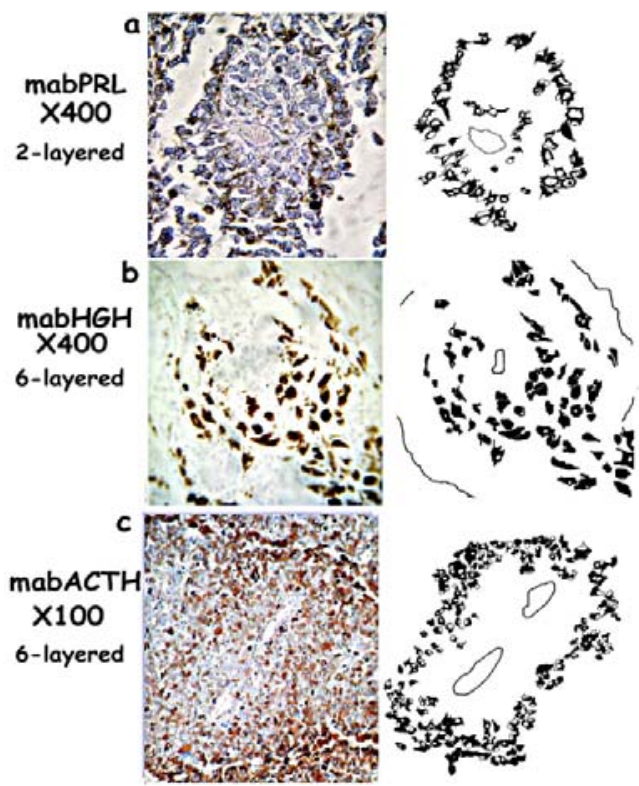




\subsubsection{Positivity in layers}

PRL positivity is high in layers L1, L2 and L3, highest being in L2 which shows $100 \%$ (all 1030 TVC) positivity while L1 and L3 show 64.2\% (661 of 1030 TVC) and 91.9\% (947 of 1030 TVC) positivity respectively. PRL is low in L4 and L5 TVCs showed $18 \%$ and $12.2 \%$ positivity (185 and 125 TVC) respectively.

\subsubsection{Positive cell counts}

The counts of immunopositive cells also reflect the same pattern. The cell counts in the PRL positive layers are: $3839 / 10576$ cells in L1 making up 36.3\%; 14008/32963 that is 42.5\% cells in L2; 39.8\%, in L3 with 18092 out of 45456 cells being positive; while only 592 out of 11839 cells (5\%) show positivity in L4; and 3.8\%, that is 382 out of 10006 cells are positive in L5.

\subsubsection{Statistical analysis}

The percentage of PRL was significantly higher $(t=11.90 ; p<0.001)$ in Layers $2-3$ (95.62 \pm 7.504$)$ compared with that in Layers 4-5 (15.64 \pm 14.65). [Mean: L2-3: 95.62; L4-5: 15.64. Std Dev: L2-3: 7.504; L4-5: 14.65]

Cells in Layers 2-3 expressed significantly higher levels of PRL (MWU $=4.5 ; t=52.5, p=0.026$, median values $=22$ ) compared to those in Layers 4-5 (median value =2.1). [Mean: L2-3: 21.28; L4-5: 2.18. Std Dev: L2-3: 19.17; L4-5: 2.02]

\subsubsection{HGH (Figure 4-5)}

\subsubsection{Positivity in layers}

The overall HGH positivity shows a pattern similar to PRL in the total number of 1030 TVCs with the highest expression being in L2 and L3. L2 shows 1025 positive TVCs (99.4\%) and L3 showed 1027 positive TVC (99.6\%). 560 TVC are positive in L1 (54.5\%); while 275 TVC (26.7\%) are positive in L4 and 229 (22.2\%) in L5.

\subsubsection{Positive cell counts}

The maximum HGH positive cells are in the layers L2 and L3 - 48.6\% (15941/32805 cells in L2 \& 23957/49199 cells in L3). There are 3566 positive cells out of 8961 cells in L1 (39.8\%). The immunopositive cells decreased to $32.8 \%$ (5773/17604 cells) in L4 and to $21.5 \%$ in L 5 (3921/18323).

\subsubsection{Statistical analysis}

The percentage of HGH was also significantly higher (MW-U $=0, t=57 ; p=0.002)$ in layers 2-3 (median values $=99.5$ ) versus that in layers 4-5 (median values = 24.45). [Mean: L2-3: 99.5; L4-5: 24.45. Std Dev: L2-3: 0.447; L4-5: 24.89]

However, there were no statistically significant differences in the levels of $\operatorname{HGH}(t=1.3 ; p=0.22)$ when cells within layers 2-3 were compared with those in layers 4-5. [Mean: L2-3: 26.16; L4-5: 15.64. Std Dev: L2-3: 7.51; L4-5: 13.47]

\subsubsection{ACTH (Figure 4-6)}

\subsubsection{Positivity in layers}

The overall expression of ACTH in the 1030 TVCs is as follows: the highest localization of ACTH is in L4 showing 788 positive TVCs (76.5\%), and in L5 showing 737 positive TVCs (71.5\%). L1 shows 162 positive TVCs (15.7\%), while L2 has 254 positive TVCs (24.7\%). 683 TVCs show positivity in L3, (66.6\%). Thus in comparison with PRL and HGH, $\mathrm{ACTH}$ is higher in the outer layers and lower in the inner layers - L1, L2 and L3.

\subsubsection{Positive cell counts}

Immunopositive cells counted in the L1 shows 130 ACTH positive cells out of total 2593 cells (5\%). L2 shows $25 \%$ cells positive for ACTH (2032/8128) while 39.1\% are positive in L3 (12819/32787). In L4 32377 out of 50431 cells are positive for ACTH (64.2\%). In comparison, the outer most layer L5 shows 61.6\% positive cells (36319/58963). 
a

Figure 5. Comparison of Hormone positivity in different layers of TVCs.

Graph comparing the hormone positivity in different layers of all 1030 fully formed TVCs. PRL and HGH positivity is significantly higher in the 2 nd and 3rd layers with high ACTH positivity in the $3 \mathrm{rd}, 4 \mathrm{th}$ and 5 th layers of the TVCs. [a] Shows the positive layers while [b] shows the $\mathrm{mAb}$ positive cell counts.

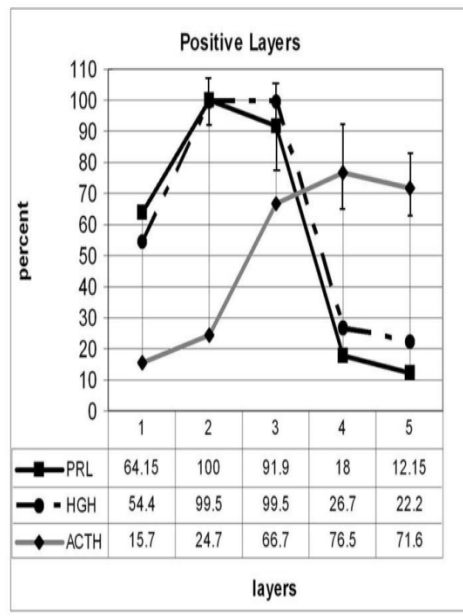

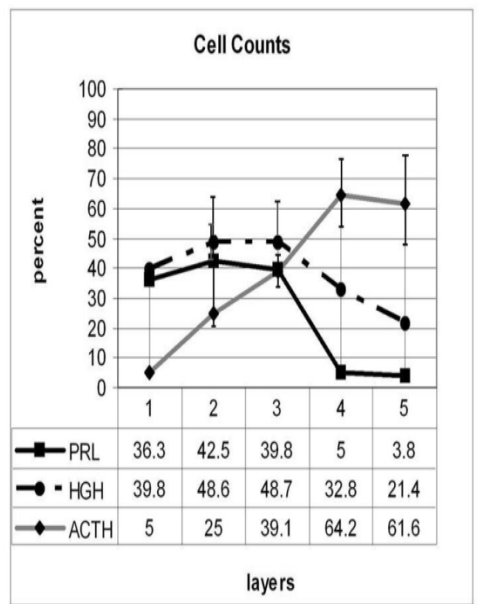

\subsubsection{Statistical analysis}

L4-L5 expressed significantly higher positivity ACTH $(t=-2.36 ; p=0.04$, mean $-46.53 \pm 27.92)$ compared to that in L2-L3 (74.62 \pm 8.40$)$. ACTH positive cells within L2-L3 did not show statistically significant difference when compared with those in L4-L5 $(t=1.3 ; p=0.22)$. [Mean: L2-3: 16.62; L4-5: 33.95. Std Dev: L2-3: 14.75; L4-5: 25.92]

\subsubsection{Pigment (Figure 6)}

a

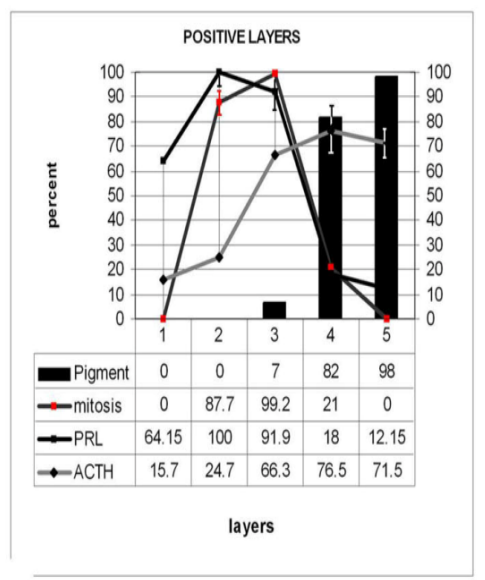

b

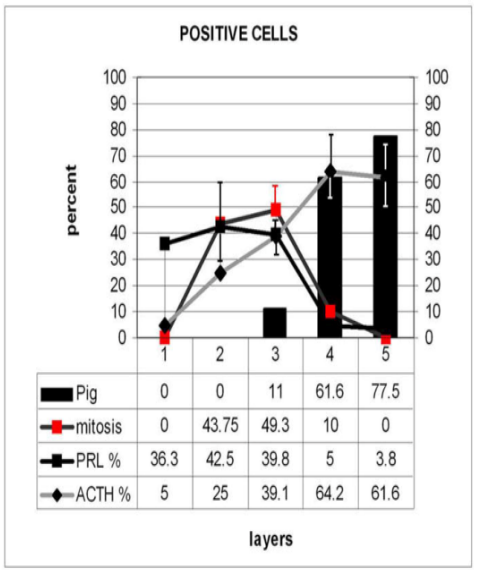

Figure 6. Correlation of mitosis \& PRL: pigment \& ACTH.

The close association between PRL/mitosis and ACTH/pigment is brought out in this comparative graph of the total number of TVCs [a] PRL and mitosis are seen in nearly all of TVCs in the 2nd and 3rd layers, while pigment and ACTH peak in the 4 th and 5th layers. [b] Cell counts of $\mathrm{mAb}$ positive cells show a similar trend.

\subsubsection{Positive layers}

The cells of the TVCs show pigment in the outer layers while the inner layers show little pigment. Layers L1 and L2 do not show any pigment while L3 shows 7\% pigment (72 TVC). In contrast layer L4 has $82 \%$ pigment (845 TVC) the greatest positivity being $98 \%$ (1009 TVCs) in L5.

\subsubsection{Positive cell counts}

Highest number of pigment positive cells are in L5 - 77.5\% (62558 of 80720 cells). L4 shows pigment positivity in 33313 of 54080 cells $(61.6 \%)$ and 380 out of 3456 cells (11\%) in L3. No pigment positive cells are seen in L1 and L2. 


\section{Discussion and conclusion}

PRL, HGH and ACTH are not the exclusive products of the pituitary. Ectopic production is commonly seen in several tumor types. It has been observed that PRL and HGH are produced by tongue tumors ${ }^{[12]}$, and colorectal carcinoma cells ${ }^{[13]}$. Ectopically produced PRL may act as a major local growth promoter via autocrine and paracrine mechanisms. Similarly, there are roughly two types of ectopic ACTH syndrome (EAS): one associated with overt malignancies and the other with occult neoplasms. The prototype of the first condition is Cushing's syndrome sustained by small-cell lung cancer (SCLC), while bronchial carcinoid tumors are the most common occult sources of ACTH.

Molecular studies have demonstrated that the carcinoid cells achieve a process of corticotroph differentiation being able to express the POMC gene and to process it correctly to release large amounts of intact ACTH. Conversely, SCLC processes POMC in an aberrant way releasing high concentrations of ACTH precursors and less intact ACTH in the circulation ${ }^{[14]}$. Carcinoid tumors have been reported in a wide range of organs but most commonly involve the lungs, bronchi, and gastrointestinal tract. They arise from neuroendocrine cells and are characterized by positive reactions to markers of neuroendocrine tissue, including neuron specific enolase and synaptophysin; and contain neurosecretory granules composed of hormones and biogenic amines e.g. serotonin ${ }^{[15]}$.

The melanocyte is of neural crest origin and also behaves as one producing neurotransmitters and neurohormones. The melanocytes form a UV-sensitive neural network in the skin ${ }^{[1]}$. Both PRL and GH are expressed by proliferating melanocytes and in response to UV exposure ${ }^{[3]}$. Prolactin expression has been observed in malignant melanomas ${ }^{[4]}$ where it may be acting as a major local peptide growth promoter via autocrine/paracrine mechanism. The expression of both PRL and its receptor in human cancer cell lines of diverse origin lends further support to its action as an autocrine/paracrine growth factor ${ }^{[16]}$.

PRL, GH and placental lactogen are class I helical cytokines believed to have arisen from a common ancestral gene. Prolactin has a dual function - as a circulating hormone and as a cytokine. This understanding is based on PRL production and distinct regulation in extrapituitary sites, binding to membrane receptors of the cytokine receptor superfamily, and activation of signaling pathways that promote cell growth and survival. One of the major targets of prolactin is the skin where it also stimulates skin melanocyte growth. There is increasing evidence that PRL plays a role in several types of cancer in reproductive and non-reproductive tissues via local production or accumulation.

The effects of PRL and GH are mediated through activation of the PRL receptor (PRLR), which belongs to the cytokine receptor superfamily ${ }^{[17]}$. Activation of PRLR initiates multiple kinase cascades, the most studied of which is the JAK-STAT pathway. Thus PRL induces transcription of members of Cyclin D family, which associate with CDKs 4 and 6 in early G1 phase of the cell cycle leading to cell cycle progression and proliferation ${ }^{[5,18]}$. Associated is an increase in cytosolic calcium concentrations with the progression through the cell cycle and exit from quiescence in early G1 phase, the G1/S transition and other checkpoints during $\mathrm{S}$ and $\mathrm{M}$ phases ${ }^{[19]}$. Physiological concentrations (0.5-5nM) of PRL result in an increase in the cytosolic free calcium concentration $\left[\mathrm{Ca}^{2+}\right]$ by stimulating $\mathrm{Ca}^{2+}$ entry (type I) and/ or inducing a mobilization of calcium ions stored in intracellular compartments (type II) ${ }^{[20]}$. Besides, there is a direct stimulation of calcium and voltage activated potassium channels $[\mathrm{Kca}]^{[21]}$.

Melanocytes also express varying levels of MSH/ACTH in response to UV exposure in correlation with repigmentation and depigmentation as seen in the marginal zone in vitiligo ${ }^{[2]}$. MSH and ACTH are both derived from pro-opiomelanocortin hormone (POMC), a large precursor glycoprotein of MW 31000, via a series of enzymatic steps in a tissue-specific manner. Melanocytes contain the full machinery for POMC processing and generation of ACTH and $\alpha$-MSH ${ }^{[22]}$. In this aspect, the melanocytes display a corticotrophin releasing hormone (CRH)-led system, organized similarly to that operating at the systemic level. 
Melanocytes respond with enhanced production of cortisol and corticosterone, which is dependent on POMC activity. This is a part of the skin's CRH/POMC system that fulfils analogous functions to the hypothalamic-pituitary-adrenal [HPA] stress axis ${ }^{[23-25]}$. Melanocytes respond to stress (UV) through production of stress hormones related to HPA axis by secretion of the POMC-derived MSH and ACTH peptides, which increase cutaneous melanin pigmentation. Pigment is, thus, the characteristic feature of a differentiated melanocyte ${ }^{[8]}$.

In the present study, the above results have indicated a definite pattern of differentiation and progression around tumor neovascular channels. All three pituitary hormones were expressed by the proliferating melanoma cells. HGH and PRL are expressed in the inner three layers, predominantly in the 2 nd and 3rd layers (Figure 1\& Figure 2). These were the layers showing a large number of mitotic figures. Pigment and ACTH were typical for in the 4th and 5th layers, where few mitotic figures were observed (Figure 5).

In the epidermal melanocytes all three hormones were expressed on UV exposure, their roles being difficult to define. In TVCs, a clear definition of the roles was evident. Taken together the results show that areas of proliferation and differentiation are clearly demarcated within the TVC, with proliferation being closer to the vessel and differentiation further from it. PRL and HGH were related to activation of the cell cycle as brought out by the presence of PRL/HGH positivity and mitotic figures in the 2 nd and 3rd layer.

Pigment, on the other hand, indicated differentiated function. ACTH positivity was associated with pigment in the 4th and 5th layer (Figure 3 and 4). ACTH stimulates pigment production during UV exposure in the epidermis. Is there a possible source of UV in the lobule? Earlier observations on melanocyte dendricity in pigmented basal cell carcinomas and seborrheoic keratosis ${ }^{[26]}$ have shown that mitotic cells are a source of biophoton emissions of UV during the separation of the DNA strands. This correlates with the presence of mitotic figures in the 2nd and 3rd layer and with expression of $\mathrm{ACTH}$ and pigment in the adjacent 4th and 5th layers (Figure 5). ACTH holds the cell in the $\mathrm{S} / \mathrm{G}_{2}$ phase in which the melanocyte produces pigment ${ }^{[27,28]}$. The absence of abundant mitosis in the outer layers reflects this function of ACTH on the melanocyte cell cycle. In TVC, ACTH/pigment expression limits or pauses the growth and enlargement of TVC at the 5th or 6th layer.

It is evident from the above observations that there is a coordinated growth of melanoma cells around neovascular channels, the cell cycle of primitive malignant melanocytes being orchestrated by the expression of the three pituitary hormones - PRL, HGH and ACTH. In the epidermis it is difficult to assign the different roles to each hormone while in the TVC the functions are clearly demarcated. PRL and HGH initiate a wave of mitotic activity releasing biophoton UV, while ACTH holds the cells in $\mathrm{S} / \mathrm{G}_{2}$ phase with pigmentation.

The above findings correlate with expression of neural markers as well as biogenic amines in the TVCs ${ }^{[29,30,31] .}$ PRL/HGH positivity associated with mitosis, coincides with the appearance of indoleamines, the presence of melatonin indicating the effect of biophoton emissions during mitosis. Similarly, catecholamine positivity in the outer layers correlates with the $\mathrm{S} / \mathrm{G}_{2}$ phase of the cell cycle, presence of ACTH and pigmentation.

\section{Acknowledgements}

I would like to acknowledge with thanks:

The Institute of Pathology (ICMR), New Delhi for the technical support;

Dr. KK Pandey, Head, Cancer Surgery Unit, Safdarjang Hospital, New Delhi for providing surgical material.

Dr. Soumya Iyengar, Associate Professor, National Brain Research Centre, Manesar, for the Statistical analysis.

\section{Conflicting interests}

The author declares that there are no conflicting interests. 


\section{References}

[1] Iyengar B: Neural differentiation as an expression of UV sensitivity of melanocytes. Acta Anat [Basel]. 1992; 143: 236-40. http://dx.doi.org/10.1159/000147254

[2] Iyengar B: Corticotropin expression by human melanocytes in the skin. Pigment Cell Res. 1995; 8: 142-6. PMid:7567790 http://dx.doi.org/10.1111/j.1600-0749.1995.tb00655.x

[3] Iyengar B: The hair follicle: a specialized UV specific receptor in the human skin. Biol Signals. 1998; 7: 188-94. $\mathrm{http} / / / \mathrm{dx}$. doi.org/10.1159/000014544

[4] Bhatavdekar JM, Balar DB, Patel DD, Chikhlikar PR, Shah NG, Suthar TP, Vondehaar BK: Expression of prolactin and its receptors in human melanoma cells: a preliminary study. In [Eds.] Iyengar B and Avantika V. Singh. Growth disorders of the pigment cell. BI Churchil Livingstone: 1996.

[5] Bole-Feysot C, Goffin V, Edery M, Binart N, Kelly PA: Prolactin [PRL] and its receptor: actions, signal transduction pathways ad phenotypes observed in PRL receptor knockout mice. Endocr Rev. 1998; 19: 225-268. PMid:9626554 http://dx.doi.org/10.1210/er.19.3.225

[6] Kim MH, Cho D, Kim HJ, Chong SJ, Lee KH, Yu DS, Park CJ, Lee JY, Cho BK, Park HJ: Investigation of the corticotropin-releasing hormone-proopiomelanocortin axis in various skin tumours. Br J Dermatol. 2006; 155: 910-5. PMid:17034518 http://dx.doi.org/10.1111/j.1365-2133.2006.07442.x

[7] Nagahama M, Funasaka Y, Fernandez-Frez ML, Ohashi A, Chakraborty AK, Ueda M, Ichihashi M: Immunoreactivity of alpha-melanocyte-stimulating hormone, adrenocortico- trophic hormone and beta-endorphin in cutaneous malignant melanoma and benign melanocytic naevi. Br. J Dermatol. 1998; 138: 981-5. http://dx.doi.org/10.1046/j.1365-2133.1998.02263.x

[8] Orlow SJ, Silvers WK, Zhou BK, Mintz B: Comparative decreases in tyrosinase, TRP-1, TRP-2, and Pmel 17/silver antigenic proteins from melanotic to amelanotic stages of syngeneic mouse cutaneous melanomas and metastases. Cancer Res. 1998; 58: 1521-3. PMid:9537258

[9] Prophet ED, Mills B, Arrington JB, Sobin LH: Laboratory Methods in Histotechnology American Registry of Pathology, Armed Forces Institute of Pathology, Washington DC; 1994.

[10] Mikel UV: Advanced Laboratory Methods in Histology and Pathology American Registry of Pathology, Armed Forces Institute of Pathology, Washington DC; 1994.

[11] Pearse AGE: Histochemistry theoretical and applied. Vol II: Analytical Technology Churchill Livingstone, London; pp 611-674; 1985.

[12] Bhatavdekar JM, Patel DD, Vora HH, Shah NG, Karelia NH, Ghosh N, Balar DB: Prolactin: its role in advanced tongue cancer. J Surg Oncol. 1994; 57: 115-20. PMid:7934062 http://dx.doi.org/10.1002/jso.2930570209

[13] Bhatavdekar JM, Patel DD, Chikhlikar PR, Shah NG, Vora HH, Ghosh N, Trivedi TI: Ectopic production of prolactin by colorectal adenocarcinoma. Dis Colon Rectum. 2001; 44: 119-27. PMid:11805572 http://dx.doi.org/10.1007/BF02234833

[14] Terzolo M, Reimondo G, Alì A, Bovio S, Daffara F, Paccotti P, Angeli A: Ectopic ACTH syndrome: molecular bases and clinical heterogeneity. Ann Oncol. 2001; 12 (Suppl): S83-7. PMid:11762358 http://dx.doi.org/10.1093/annonc/12.suppl_2.S83

[15] Penezić Z, Savić S, Vujović S, Tatić S, Ercegovac M, Drezgićc M: The ectopic ACTH syndrome. Srp Arh Celok Lek. 2004; 132: 28-32. PMid:15227962 http://dx.doi.org/10.2298/SARH0402028P

[16] Ben-Jonathan N, Liby K, McFarland M, Zinger M: Prolactin as an autocrine/paracrine growth factor in human cancer. Trends Endocrinol Metab. 2002; 13: 245-50. http://dx.doi.org/10.1016/S1043-2760(02)00603-3

[17] Clevenger CV, Kline JB: Prolactin receptor signal transduction. Lupus. 2001; 10: 706-718. PMid:11721697 http://dx.doi.org/10.1191/096120301717164949

[18] Brockman JL, Schroeder MD, Schuler LA: PRL activates the cyclin G1 promoter via the JAK2/ Stat pathway. Mol Endocrinol. 2002; 16: 774-784. PMid:11923474 http://dx.doi.org/10.1210/me.16.4.774

[19] Berridge MJ: Inositol trisphosphate and calcium signalling. Nature. 1993; 361: 315-325. PMid:8381210 http://dx.doi.org/10.1038/361315a0

[20] Vacher P, Van Chuoi MT, Paly J, Djiane J, Dufy B: Short term effect of prolactin on intracellular calcium in Chinese hamster ovary cells stably transfected with prolactin receptor complementary deoxyribonucleic acid. Endocrinol. 1994; 134: $1213-1218$. PMid:8119161 http://dx.doi.org/10.1210/en.134.3.1213

[21] Prevarskaya NB, Skryma R, Vacher P, Daniel N, Bignon C, Djiane J, Dufy B: Early effects of PRL on ion conductances in CHO cells expressing PRL receptor. Am J Physiol. 1994; 267: C554-C562. PMid:7521130

[22] Rousseau K, Kauser S, Pritchard LE, Warhurst A, Oliver RL, Slominski A, Wei ET, Thody AJ, Tobin DJ, White A: Proopiomelanocortin [POMC], the ACTH/melanocortin precursor, is secreted by human epidermal keratinocytes and melanocytes and stimulates melanogenesis. FASEB J. 2007; 21: 1844-56. PMid:17317724 http://dx.doi.org/10.1096/fj.06-7398com 
[23] Slominski A, Wortsman J, Pisarchik A, Zbytek A, Linton EA, Mazurkiewicz J, Wei ET: Cutaneous expression of corticotropin releasing hormone [CRH], urocortin and CRH receptors. FASEB J. 2001; 15: 1678-1693. PMid:11481215 http://dx.doi.org/10.1096/fj.00-0850rev

[24] Slominski A, Tobin DJ, Shibahara S, Wortsman J: Melanin Pigmentation in Mammalian Skin and Its Hormonal Regulation. Physiol. Rev. 2004; 84: 1155-1228. PMid:15383650 http://dx.doi.org/10.1152/physrev.00044.2003

[25] Ziegler CG, Krug AW, Zouboulis CC, Bornstein SR: Corticotropin releasing hormone and its function in the skin. Horm Metab Res. 2007; 39: 106-9. PMid:17326006 http://dx.doi.org/10.1055/s-2007-961809

[26] Iyengar B: UV guided dendritic growth patterns and the neural networking of melanocytes. Experientia. 1994; 50: 669-672. PMid:7913446 http://dx.doi.org/10.1007/BF01952870

[27] Iyengar B, Timar J, Szende B: Modulation of cell cycle traverse in the amelanotic cells of vitiligo and melanomas. The interphase between aplasia and neoplasia. In Iyengar B, Avantika V. Singh [ed] Growth Disorders of the Pigment Cell. BI Churchill Livingstone, New Delhi, pp220-233. 1996.

[28] Tsatmali MJ, Ancans, Thody AJ: Melanocyte function and its control by melanocortin peptides. J Histochem Cytochem. 2002; 50: 125-33. PMid:11799132 http://dx.doi.org/10.1177/002215540205000201

[29] Iyengar, B, Singh, AV: Patterns of neural differentiation in Melanomas. Journal of Biomedical Science. 2010; $17: 87$. PMid:21080952 http://dx.doi.org/10.1186/1423-0127-17-87

[30] Iyengar, B: Biogenic amines and tumor-vascular interaction in melanomas. Journal of Solid Tumors, 2011; 1: 44-55. http://dx.doi.org/10.5430/jst.v1n2p44

[31] Iyengar, B: Multipotent Astrocytic Stem Cells Identified During Angiogenesis in Web Central. 2011; WMC002407. 